\title{
Differential Effects of Damage within the Hippocampal Region on Memory for a Natural, Nonspatial Odor-Odor Association
}

\author{
Pablo Alvarez, Paul A. Lipton, Rebecca Melrose, and Howard Eichenbaum ${ }^{1}$ \\ Laboratory for Cognitive Neurobiology, Department of Psychology, Boston University, Boston, Massachusetts 02215, USA
}

\begin{abstract}
Debate continues on whether the role of rodent hippocampus in memory is limited to the spatial domain. Recently, this controversy has been addressed with studies on the social transmission of food preference, an odor-odor association task with no spatial requirements. Multiple reports have concluded that damage to the hippocampal region impairs memory in this task, but there remain questions about the extent of damage essential to produce an impairment. Furthermore, a recent study (Burton et al. 2000) found no effect of hippocampal lesions on memory in this task. We tested animals with complete lesions of the hippocampus (H) lesions of the hippocampus plus subiculum (HS), and lesions of the adjacent, anatomically related cortices of the parahippocampal region (PHR). H lesions produced an impairment on spatial delayed alternation, but not on memory for the social transmission of food preference, whereas HS and PHR lesions produced severe and equivalent impairments on memory for the socially acquired food preference. We discuss possible explanations for the discrepancy with the results of Burton et al. (2000) and conclude that the hippocampus and subiculum together play a critical role in the formation of this form of nonspatial, relational memory.
\end{abstract}

The hippocampal region is composed of a set of brain structures in the temporal lobe, including the hippocampus $(\mathrm{H})$, the subiculum (S), and the parahippocampal region (PHR, composed of distinct entorhinal, perirhinal, and postrhinal/ parahippocampal [in rats/primates] cortices; Squire 1992; Eichenbaum et al. 1994). There is general agreement that in humans these structures mediate declarative or explicit memory (Squire et al. 1993; Schacter and Tulving 1994). In animals who cannot declare their knowledge directly, a debate continues on whether the role of $\mathrm{H}$ is limited to spatial memory (O'Keefe and Nadel 1978; Nadel 1991) or extends beyond it (Sutherland and Rudy 1989; Eichenbaum et al. 1992). Several studies have now shown that damage to $\mathrm{H}$ or its connections produce a deficit on nonspatial memory tasks where animals must learn stimulus relationships and/ or respond flexibly during memory expression (Alvarez et al. 1995; Bunsey and Eichenbaum 1995, 1996; Dusek and Eichenbaum 1997, 1998), and conversely, that animals with hippocampal region damage can exhibit intact spatial learning when they are not required to use stimulus relations and flexible memory expression (Eichenbaum et al. 1990; Whishaw and Jarrard 1996; Whishaw and Tomie 1997). These findings support the hypothesis that the hippocampal region is crucial for forming flexible relationships between to-be-remembered stimuli in any modality (Eichenbaum et al. 1992) and that impairment is seen on spatial

${ }^{1}$ Corresponding author.

E-MAIL hbe@bu.edu; FAX (617) 353-1414.

Article and publication are at www.learnmem.org/cgi/doi/ $10.1101 / \mathrm{lm} .38201$. tasks only when they involve a strong demand for encoding and using spatial relationships.

One memory task that has no spatial component but requires flexible expression of stimulus associations is the social transmission of food preference task (Galef and Wigmore 1983; Strupp and Levitsky 1984). In this paradigm a "demonstrator" rat is fed an odorous food and then presented to the subject. During this social contact, the subject acquires an association between the food odor and odorous constituents of the demonstrator's breath of a conspecific (Galef et al. 1988). Subsequently, the subject expresses this association by showing a preference for the same food odor. This memory is not dependent on the spatial context where the training occurred (Beck and Galef 1989; P. Alvarez and A. Vale-Martinez, unpubl.). Together, these data suggest that spatial information makes a negligible contribution to the learning and retention of socially acquired food preferences. This task does, however, exhibit some of the key characteristics of relational or declarative memory, in that the information can be acquired quickly (in one or a few exposures) and the memory has to be expressed flexibly, that is, in a test situation (food selection) very different from the circumstances of the original learning (a social encounter).

Winocur (1990) first showed that radiofrequency lesions of the dorsal $\mathrm{H}$ result in an impairment in retention of the social transmission of food preferences. Subsequently, we reported that selective neurotoxic lesions of the $\mathrm{H}$ plus $\mathrm{S}$ (HS), but not of $\mathrm{H}$ alone or $\mathrm{S}$ alone, also impaired performance on this task (Bunsey and Eichenbaum 1995). How-

LEARNING \& MEMORY 8:79-86 @ 2001 by Cold Spring Harbor Laboratory Press ISSN1072-0502/01 \$5.00

$$
\begin{array}{lllllllllllllll}
\text { L } & E & A & R & N & I & N & G \quad & \mathbb{Z} & M & E & M & O & R & Y
\end{array}
$$


ever, in the latter study, it was also possible that the impairment in the joint HS group was due to increased damage to $\mathrm{H}$ and $\mathrm{S}$ present in this group and absent in the $\mathrm{H}$ and $\mathrm{S}$ groups. Mutations that affect hippocampal function in mice have also been shown to impair performance on this task (Kogan et al. 1997; Mayeux-Portas et al. 2000; Rampon et al. 2000). On the other hand, a recent study (Burton et al. 2000) found no effect of HS lesions on this task, and concluded that the role of HS was limited to spatial memory.

An elaboration of the relational memory theory proposed that $\mathrm{H}$ and $\mathrm{S}$ are necessary for the formation of relational memories, whereas the adjacent cortices of the PHR are involved in maintaining intermediate-term storage of individual items (Eichenbaum et al. 1994). This view of differential functions of components within the hippocampal region suggests that different patterns of impairment should be observed, depending on the locus of the lesion. However, in cases where hippocampal lesions have been directly compared with larger lesions of the system including the PHR, progressively greater damage to this system has typically been found to produce a progressively greater memory impairment, especially on nonspatial tasks (Mumby and Pinel 1994; Zola-Morgan et al. 1994). This observation may not contradict the possibility of differential functions because almost all cortical inputs to the $\mathrm{H}$ pass through the PHR, making a straightforward double dissociation unlikely. Based on this anatomical fact, for memory performance that is dependent primarily on the PHR, one should expect to observe a greater deficit with PHR lesions than with $\mathrm{H}$ lesions. However, for memory performance that is mainly dependent on $\mathrm{H}$ and/or $\mathrm{S}$, lesions of $\mathrm{H}$ and/or $S$ and lesions of the PHR that interrupt cortical connections to these areas should have a similar magnitude of effect. More specifically, based on these considerations, to the extent that $\mathrm{H}$ and $\mathrm{S}$ are responsible for relational memory, then it should be possible to find a test of relational memory in which the impairment produced by PHR lesions is no greater than that produced by HS lesions (Squire et al. 1994).

The present study therefore addressed the following questions: 1) Does damage to $\mathrm{H}$ and $\mathrm{S}$ reliably produce an impairment in this nonspatial task? 2) What is the extent of damage to $\mathrm{H}$ and $\mathrm{S}$ necessary to produce a deficit? 3) Is performance on the task exclusively dependent on HS or also on the PHR? We tested animals with lesions of $\mathrm{H}, \mathrm{HS}$, or PHR on the social transmission of food preference task by using two different retention delays (15 $\mathrm{min}$ and $1 \mathrm{wk}$ ).

\section{RESULTS}

\section{Lesions}

Group $H$

As shown on Figure 1, the lesions in this group involved essentially all of $\mathrm{H}$ (including Amman's horn and the dentate gyrus), as well as approximately half of S. Sparing of $\mathrm{H}$ was generally limited to the ventral tip of the dentate gyrus. Spared S typically included portions of both dorsal and ventral S. Damage to entorhinal cortex averaged $4 \%$. One animal with an intended $\mathrm{H}$ lesion had more extensive subicular damage (95\%) and was included in group HS, and two animals with an intended HS lesion that had substantial sparing of $\mathrm{S}$ ( $47 \%$ and $37 \%$ damage) were included in group $\mathrm{H}$.

\section{Group HS}

As for the $\mathrm{H}$ group, the lesions in this group involved essentially all (95\%) of H. HS lesions also included the great majority of S (>80\%; Fig. 1). Sparing of $\mathrm{H}$ was generally limited to the ventral tip of the dentate gyrus. Spared $S$ typically included small portions of ventral or posterior $\mathrm{S}$. Damage to entorhinal cortex was small and averaged $18 \%$. In some animals, there was also damage to the amygdala and/or the caudate/putamen.

\section{$H$ versus $H S$ Lesions}

Table 1 summarizes the amount of damage to each structure. There was no difference between groups $\mathrm{H}$ and HS in the extent of damage to $\mathrm{H}$ [H: $97 \%$; HS: $95 \%$; $t(13)=1.3$, $P>0.2$ ], but there was a significant difference in the extent of damage to S [H: $53 \%$; HS: $89 \%$; $t(13)=5.4, P<0.001]$ and to entorhinal cortex [H: $4 \%$; HS: $18 \% ; t(13)=2.6, P<0.05$ ]

\section{Group PHR}

Animals in this group suffered extensive damage to the entorhinal, perirhinal, and postrhinal cortices (Fig. 1). In addition, the lesion typically included portions of area TE3 and some damage to posterior pyriform cortex and the amygdala, and occasionally to the posterior ventral caudate/putamen. In three animals, the damage extended into $\mathrm{H}$ itself on one side. Two animals had mainly unilateral damage to the PHR and were excluded from all analyses.

\section{Odor-Odor Association Task}

Figure $2 \mathrm{~A}$ presents the data from this task. Results for all sham-lesioned groups were similar $[F(2,20)=0.07$, $P>0.9]$; therefore, they were considered together in the data analyses as group N. This group showed robust learning (scores of $79 \%$ and $74 \%$, indicating they ate approximately three to four times more of the trained food than the comparison food). A two-way ANOVA (lesion $\times$ delay) showed a significant effect of group $[F(3,50)=7.7$, $P<0.0001]$. The effect of delay did not reach significance $[F(1,50)=2.7, P>0.1]$, and there was no group $\times$ delay interaction $[F(3,50)=.39, P>0.7]$. As indicated by the lack of a significant delay effect, scores were similar at $15 \mathrm{~min}$ and $1 \mathrm{wk}(\mathrm{N}: 79 \%, 74 \%$, H: $81 \%, 81 \%$, HS: $62 \%, 56 \%$, PHR: $63 \%, 55 \%)$. Post-hoc Newman-Keuls tests were therefore performed on the mean retention score, showing that groups HS and PHR groups performed significantly worse

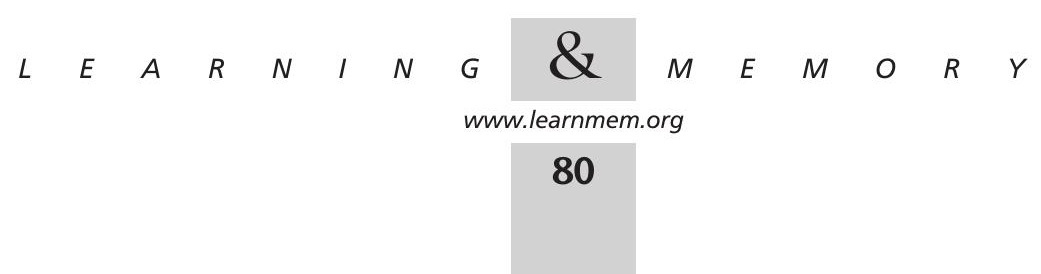



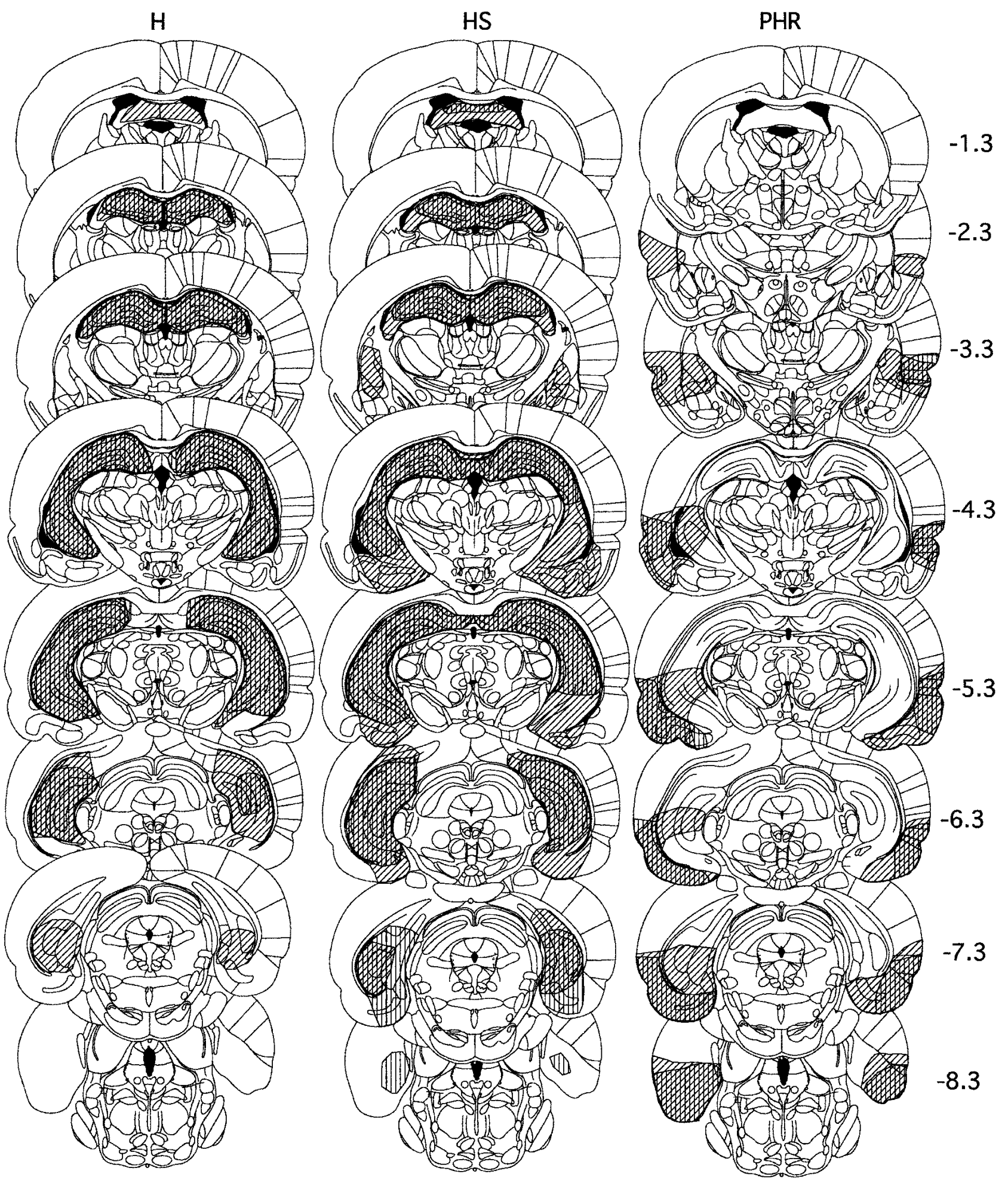

Figure 1 Extent of the smallest (vertical hatching) and largest (diagonal) lesions in each group. Numbers indicate millimeters posterior to bregma.

than groups $\mathrm{N}$ and $\mathrm{H}$. Groups HS and PHR did not differ from each other, and neither did groups $\mathrm{H}$ and N. Groups N,
$\mathrm{H}$, and PHR each had overall scores significantly different from chance (one-sample $t$-test, all $t s>3.3$, all $p s<0.005$ ),

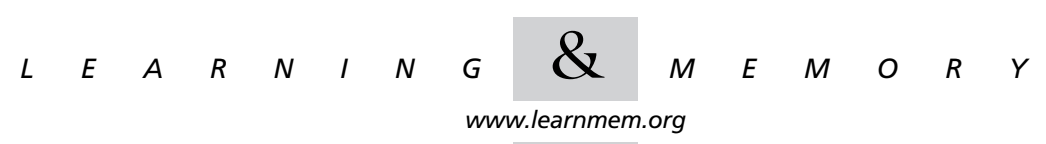


Table 1. Lesion Coordinates and Volumes for $\mathrm{H}$ and HS Lesions

\begin{tabular}{|c|c|c|c|c|c|c|c|c|c|c|c|c|c|c|}
\hline \multicolumn{15}{|l|}{ H lesions } \\
\hline Posterior from bregma & 2.4 & 3.0 & 3.0 & 3.0 & 4.0 & 4.0 & 4.0 & 4.8 & 4.8 & 4.8 & 5.7 & 5.7 & 5.7 & 5.7 \\
\hline Lateral from bregma & -1.0 & -1.4 & -1.4 & -3.0 & -2.1 & -2.1 & -3.7 & -5.1 & -4.1 & -4.1 & -4.5 & -5.1 & -5.1 & -5.1 \\
\hline Ventral (from dura) & 3.2 & 2.8 & 3.4 & 3.0 & 2.3 & 3.3 & 3.0 & 7.0 & 3.5 & 7.2 & 3.6 & 4.5 & 5.5 & 6.8 \\
\hline Volume (1) & 0.18 & 0.09 & 0.09 & 0.18 & 0.09 & 0.09 & 0.18 & 0.18 & 0.09 & 0.18 & 0.18 & 0.12 & 0.12 & 0.12 \\
\hline \multicolumn{15}{|l|}{ HS lesions } \\
\hline Posterior from bregma & 2.4 & 3.0 & 3.0 & 3.0 & 4.0 & 4.0 & 4.0 & 4.8 & 4.8 & 4.8 & 5.7 & 5.7 & 5.7 & 5.7 \\
\hline Lateral from bregma & -1.0 & -1.4 & -1.4 & -3.0 & -2.1 & -2.1 & -3.7 & -5.1 & -4.1 & -4.1 & -4.5 & -5.1 & -5.1 & -5.1 \\
\hline Ventral (from dura) & 3.2 & 2.8 & 3.4 & 3.0 & 2.3 & 3.3 & 3.0 & 8.0 & 3.5 & 7.2 & 3.6 & 4.5 & 5.5 & 7.4 \\
\hline Volume (1) & 0.2 & 0.1 & 0.1 & 0.2 & 0.1 & 0.1 & 0.2 & 0.2 & 0.1 & 0.2 & 0.2 & 0.14 & 0.14 & 0.14 \\
\hline
\end{tabular}

but group HS, whose scores had higher variance (Fig. 2A), did not $[t(6)=0.9, P>0.4]$. All groups ate similar amounts of food during the testing sessions $[\mathrm{F}(3,47)=1.7, P>0.1]$.

\section{Spatial Delayed Alternation}

To verify that the $\mathrm{H}$ lesions in this study had a behavioral effect, we tested five animals from the $\mathrm{H}$ group, seven animals from the PHR group, and nine control animals ( $5 \mathrm{Sh}-\mathrm{H}$, 4 Sh-PHR) on spatial delayed alternation in a T-maze (Fig.

\section{A. Social transmission of food preference}
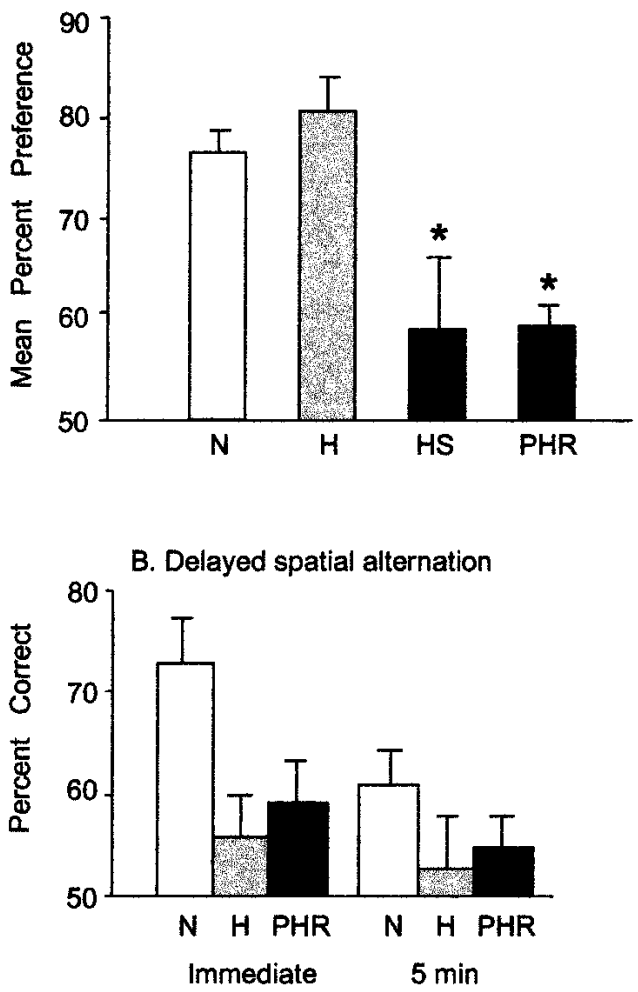

Figure 2 Performance on behavioral tasks. (A) Social transmission of food preference. Asterisks indicate a significant difference from both the $\mathrm{H}$ and $\mathrm{N}$ groups. (B) Delayed spatial alternation. All data are presented as mean + S.E.M. On both tasks, 50\% represents chance performance.
2B). Because there were no differences between the Sh-H and Sh-PHR animals $(P>0.1)$, they were considered together as group N. A two-way analysis of variance (group $\times$ delay) showed a significant effect of group $[F(2,18)=7.5$, $P<0.005]$. The effect of delay did not reach significance $[F(1,18)=3.1, P=0.09]$, and there was no group $\times$ delay interaction $[F(2,18)=0.9, P>0.4]$. Post-hoc NewmanKeuls tests on the mean performance score showed that groups $\mathrm{H}(51 \%)$ and PHR (57\%) performed significantly worse than group $\mathrm{N}(67 \%)$, but did not differ from each other. The performance of groups $\mathrm{H}$ and PHR did not differ significantly from chance $(t s<2.1, p s>0.08)$, but that of group $\mathrm{N} \operatorname{did}[t(8)=6.6, P<0.0002]$

\section{DISCUSSION}

Social transmission of food preference, an odor-odor association task, was impaired to the same extent by conjoint lesions of $\mathrm{H}$ and $\mathrm{S}$, and by lesions of PHR that disconnect $\mathrm{H}$ and $\mathrm{S}$ from all cortical input. However, lesions of $\mathrm{H}$ that also included approximately half of S did not produce an impairment, even though these lesions reduced performance to chance on a spatial delayed alternation task.

\section{Complete Lesions of HS Are Needed to Produce an Impairment in Socially Transmitted Food Preference}

A previous study (Bunsey and Eichenbaum 1995) found that separate lesions of $\mathrm{H}$ or $\mathrm{S}$ did not produce an impairment on the social transmission of food preference task, but conjoint lesions did. However, in this study, the conjoint lesions included more damage to both $\mathrm{H}$ and $\mathrm{S}$ than did the separate lesions. Thus, the extra hippocampal damage, the extra subicular damage, or both together could have been responsible for the impairment in the HS group. The $\mathrm{H}$ and $\mathrm{HS}$ groups described here have equivalent, and very extensive (>95\%) damage to $\mathrm{H}$, including the ventral $\mathrm{H}$. Animals in the HS group were impaired and had much more extensive $(\sim 90 \%)$ damage to $\mathrm{S}$ than did animals in the $\mathrm{H}$ group $(\sim 50 \%)$, which performed normally. Thus, the present results suggest that complete damage to $S$ is necessary to produce an impairment in social transmission of food preference, quite possibly in conjunction with damage to $\mathrm{H}$. Determining

$$
\begin{array}{lllllllllllllll} 
& E & A & R & N & I & N & G & \mathcal{Q} & M & E & M & O & R & Y \\
\text { www.learnmem.org } & &
\end{array}
$$


whether complete damage to $S$ alone would be sufficient to produce an impairment, or whether additional damage to $\mathrm{H}$ is also needed, will require further studies with selective lesions of $\mathrm{S}$ that do not damage $\mathrm{H}$.

The present set of data cannot rule out the possibility that additional damage to entorhinal cortex in the HS group (18.5\%) compared with the $\mathrm{H}$ group (4\%) was responsible for the impairment. Nevertheless, we believe that it is unlikely that the additional small entirhinal cortex damage accounts for the deficit. First, there was no clear relationship between performance and entirhinal cortex damage; for example, the worst performer in the HS group had only $8 \%$ damage to entirhinal cortex (the second least), whereas the best performer had damage of $15 \%$, close to the group average. Moreover, even the largest lesions in the HS group in our previous study (Bunsey and Eichenbaum 1995) included minimal or no entirhinal cortex damage, but this group did show a severe impairment in social transmission of food preference. Thus, entirhinal cortex damage is not a requirement for an impairment in social transmission of food preference.

The conclusion that nearly complete damage to S, possibly in addition to hippocampal damage, is needed to impair social transmission of food preference appears to contradict several pieces of evidence suggesting that hippocampal damage alone can produce an impairment. The original results of Winocur (1990) showed an impairment with dorsal hippocampal lesions. More recently, Winocur et al. (2001) found both anterograde and retrograde memory impairments in rats with hippocampal lesions. Finally, mice with a gene knockout selective to hippocampal area CA1 were also impaired in learning socially transmitted food preferences (Rampon et al. 2000). On closer examination, however, all of these results are compatible. Electrolytic lesions of the dorsal $\mathrm{H}$ (Winocur 1990) can also damage dorsal S and, most importantly, interrupt fibers of passage within the alveus and fornix to and from the entire $S$. This disconnection of $\mathrm{S}$ (and of ventral $\mathrm{H}$ ) from subcortical areas could explain the impairment observed. In the more recent study (Winocur et al. 2001), the exact extent of damage to $\mathrm{S}$ was not measured, but the large hippocampal lesions appear to have included at least some $S$ damage, according to their Figure 1. In addition, the impairment produced by these lesions was small and fell slightly short of significance $(P=0.058)$ in spite of the large number of subjects (20 lesioned animals and 33 control animals). Also, the subjects had only one 15-min exposure to a demonstrator that had eaten the trained food, rather than three 20-min interactions, as in the present study. Thus, lesions of $\mathrm{H}$ and portions of S, which were ineffective in the present study, may have been sufficient to produce a mild impairment when the information was learned less strongly (only one interaction). Finally, the fact knocking out a particular receptor (the NMDA-R1 receptor) selectively within CA1 impairs so- cial transmission of food preference in mice (Rampon et al. 2000) raises questions about possible species differences in the learning of this task. However, the specificity of the knockout to CA1 appears to be time limited (Rampon et al. 2000), in that the loss of NMDA-R1 spreads to other areas in older (6-mo) animals. Thus, it is not clear whether, at the time the mice were tested, NMDA-R1 activity might also have been reduced in other areas, including $\mathrm{S}$.

The combined data therefore suggest that, although damage to $\mathrm{H}$ alone (and, indeed, damage limited to dorsal $\mathrm{H}$; Moser et al. 1995) is sufficient to produce an impairment on some spatial tasks, complete damage to $\mathrm{H}$ and $\mathrm{S}$, or possibly only to $\mathrm{S}$, is needed to produce a consistent and severe impairment on social transmission of food preference.

\section{PHR Lesions Produce an Impairment No Greater Than That Produced by HS Lesions}

A second finding of the present study is that PHR lesions produce an impairment that is equivalent to, but not greater than, that produced by HS lesions. The similarity in the magnitude of the impairment following HS and PHR lesions cannot be caused by a floor effect, because the PHR group's performance was significantly above chance. The PHR lesion interrupts all cortical input to and output from HS and therefore represents a major disconnection of the whole hippocampal region including both PHR and HS. Thus, the finding that the impairment was similar between the two groups at both delays (15 min and $1 \mathrm{wk}$; see Fig. 2) suggests that adding more cortical damage does not exacerbate the impairment produced by an HS lesion.

The present pattern of findings is similar to the observation of equivalent deficits following hippocampal or fornix lesions and PHR lesions on nonspatial transverse patterning and transitive inference tasks (Dusek and Eichenbaum 1997, 1998), and on spatial learning in the present study and other studies (e.g., Olton et al. 1982). The finding that both HS and PHR produce similar, severe impairments points to both of these areas playing necessary, but not sufficient, roles in these tasks. One obvious critical role for the cortices of the PHR is to provide communication between $\mathrm{H}$ and cerebral cortex (such as information about the odors used in the present task). Although this suggests that the HS may be the key structure involved in forming the associations needed to perform the task, the possibility that the cortices of the PHR make other necessary contributions (e.g., preprocessing of the olfactory information into a form that the $\mathrm{H}$ can process) cannot be ruled out. Indeed, because of the anatomy of the system, it would be very difficult to produce a convincing double dissociation.

However, these findings can be contrasted with the pattern of impairments following $\mathrm{H}$ or HS versus PHR lesions on some other memory tasks. For example, deficits in visual recognition memory tasks (delayed nonmatching to sample, easy object discrimination) were consistently exac-

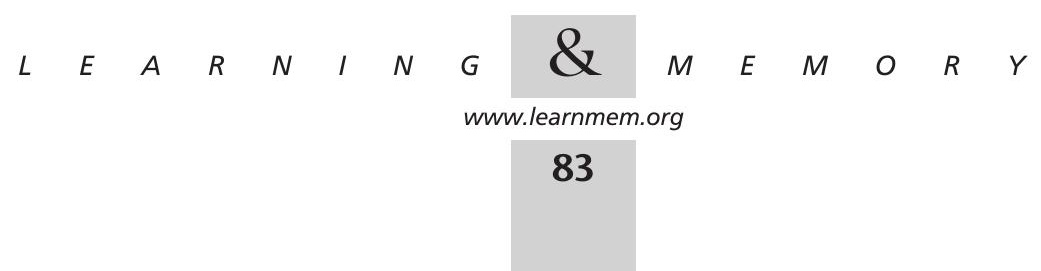


erbated by additional cortical damage in monkeys (ZolaMorgan et al. 1994) as well as in rats (Mumby and Pinel 1994). This combination of findings is consistent with the proposal that the roles of the $\mathrm{H}$ (including or not including the $S$ ) and the PHR in memory are not equivalent. According to one proposal, the PHR plays a greater role in tasks that require maintenance of a single item in memory, whereas the $\mathrm{H}$ itself is critical in relational memory tasks such as social transmission of food preference (Eichenbaum et al. 1994).

\section{Is the Impairment Produced by HS Lesions Reliable?}

The results of the present study, as well as others discussed earlier (Winocur 1990; Kogan et al. 1997; Rampon et al. 2000; Winocur et al. 2001; Mayeux-Portas et al. 2001) contrast with the conclusions of a recent study (Burton et al. 2000) in which HS lesions did not produce an impairment, and sometimes produced facilitation, in the social transmission of food preference task. One possible explanation is that, because the present study indicates that the exact extent of damage to $\mathrm{H}$ and $\mathrm{S}$ is crucial, the differences between the studies are due to lesion differences. The extent of damage to HS in Burton et al.'s animals varied between $55 \%$ and $99 \%$, with substantial sparing of $\mathrm{H}$ and some $\mathrm{S}$ in the animals with the smallest lesions according to their Figure 7, which could explain the lack of an overall group impairment. A more important potential source of the discrepancy comes from the fact that the control animals in Burton et al.'s study performed quite poorly (61\% at the immediate delay and $62 \%$ at 1 day). This level is similar to that of the lesioned animals in the present study, rather than to that of the control animals $(79 \%$ at $15 \mathrm{~min}$ and $74 \%$ at 1 wk). Thus, it is likely that the protocol used by Burton et al. did not allow for good transmission of the food preference. We have found (P. Alvarez and H. Eichenbaum, unpubl) that sometimes a single exposure is insufficient to produce consistent and lasting memory, and therefore have adopted a multiple exposure protocol. To obtain above-chance preference choices, Burton et al. instead resorted to increasing the odorant concentrations fourfold. The combination of increased odor concentrations and marginal learning suggests that the subjects in that study may not have been learning a socially transmitted food preference in the usual way, but rather were acquiring some other type of information. For example, they may simply have been expressing an adaptation to neophobia for the trained food. Under normal circumstances, socially transmitted food preferences are not mediated by changes in neophobia in rats, but rather by the association of the food odor with cues in the demonstrator rat's breath. For example, Galef and Stein (1985) showed that a rat surrogate made of cotton batting and sprinkled with a trained food was ineffective in inducing food preference, whereas live rats sprinkled with the trained food on their noses were effective. Moreover, a rat surrogate sprinkled with the trained food was effective in inducing food preference if also sprinkled with carbon disulfide, a major odorous constituent of rat breath (Galef et al. 1988). In addition, a dissociation has been shown between impaired performance on social transmission of food preference and normal neophobia in mice with a Thy 1 null mutation that alters hippocampal physiology (Mayeux-Portas et al. 2000).

However, it is possible that if social transmission was ineffective, and the odor of the food present, for example, on the demonstrator's fur was strong enough, that odor would have become somewhat familiar to the experimental subjects. Then, in the testing phase, when presented with a choice between two foods, they would be expected to eat slightly more of the food whose odor was somewhat familiar and therefore induced less neophobia. This might explain the low levels of performance (61\%) seen in the Burton et al. study, as well as the lack of an impairment, because hippocampal lesions would not be expected to affect the adaptation to neophobia. Whatever the underlying cause, the low level of performance in Burton et al.'s normal animals suggests that social transmission of food preference was not taking place in the same way as in previous studies (Galef et al. 1988; Winocur 1990; Bunsey and Eichenbaum 1995).

In summary, we found that when normal controls exhibit robust learning in an odor-odor association task, joint damage to $\mathrm{H}$ and $\mathrm{S}$ is necessary and sufficient to produce a severe impairment, and that damage to the PHR also produces, but does not exacerbate, this impairment. These findings support the idea that $\mathrm{H}$ and $\mathrm{S}$ together play a critical role in the formation of nonspatial, relational memories.

\section{MATERIALS AND METHODS}

\section{Subjects}

Fifty-six Long-Evans male rats were used. Animals weighed 225-300 $\mathrm{g}$ at the beginning of the experiment. Animals were housed singly, kept on a 12/12 light cycle, and were food-deprived before training and testing sessions by allowing them only four food pellets in the previous $24 \mathrm{~h}$. The animals were subdivided in groups as follows:

1. Seven underwent ibotenate lesions of $\mathrm{H}$.

2. Four underwent sham lesions of $\mathrm{H}(\mathrm{Sh}-\mathrm{H})$.

3. Eight underwent ibotenic acid lesions of HS.

4. Eight underwent sham lesions of $\mathrm{H}$ and $\mathrm{S}$ (Sh-HS)

5. Eighteen underwent aspiration lesions of PHR, including the entorhinal, perirhinal, and postrhinal cortices.

6. Eleven underwent sham lesions of PHR (Sh-PHR).

\section{H, HS, and Sham Surgeries}

Animals were anesthetized with sodium pentobarbital $(65 \mathrm{mg} / \mathrm{kg}$, intraperitoneal). After placement in the stereotaxic apparatus, the skull was exposed and bregma and lambda were made level. Skull flaps were removed bilaterally over the lesion sites. For the shamlesioned groups, small punctures were made in the dura with a

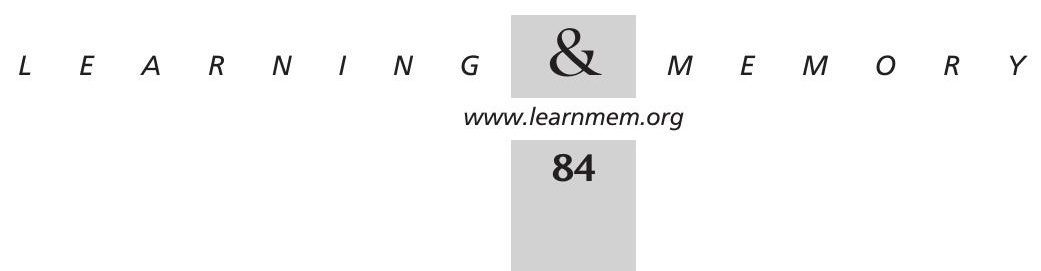


25-gauge needle on each side of the brain at each lesion site. For the $\mathrm{H}$ and HS groups, a Hamilton Syringe was lowered to the stereotaxic coordinates shown in Table 2 , and ibotenic acid $(10 \mu \mathrm{g} / \mu \mathrm{l})$ was injected. The height of the dura used as origin for the dorsoventral coordinates was measured at 4.8 posterior to bregma and 4.1 lateral to midline ipsilateral to the injection site. The syringe was allowed to remain at each site for at least $1 \mathrm{~min}$ after the injection was completed to ensure that all of the toxin was absorbed into the tissue. After the injections were complete, the skin was sutured, and a topical antibiotic (Panolog cream) was applied to the sutured area to prevent infection.

\section{PHR and Sham Surgery}

Animals were placed in a custom-designed headholder that allowed unobstructed bilateral access to the temporal surface of the skull. A midline incision was made in the scalp, and the skin and fascia were retracted. The temporal muscle was then retracted bilaterally until the base of the zygomatic arch was clearly visible. A dental drill and fine-tipped rongeurs were used to remove the skull and expose the underlying perirhinal and entorhinal cortices. For sham-lesioned animals, the skull was only partially drilled. The tissue was aspirated under visual guidance by using a blunt, curved 22-gauge needle connected to a vacuum. To additionally remove the postrhinal cortex, we removed the tissue posterior and dorsal to the end of the craniotomy. Bleeding was controlled with ice-cold saline solution. Once the cortical removal was complete and bleeding had stopped, the opening was packed with saline-soaked Gelfoam, the temporal muscle was repositioned, the skin was sutured, and a topical antibiotic (Panolog cream) was applied.

\section{Odor-Odor Association Task: Social Transmission of Food Preference}

All animals were allowed to recover from surgery for at least $2 \mathrm{wk}$ before training began. Subsequently, they were handled, allowed to habituate to the testing room, and trained to eat ground rat chow from 4-ounce Nalgene cups $(6.4-\mathrm{cm}$ high $\times 6.2-\mathrm{cm}$ diameter) attached with Velcro to black Plexiglas bases $(10 \mathrm{~cm} \times 17 \mathrm{~cm})$ that were placed in the animals' cages. The odor pairs used were Clove $(0.25 \%$ in rat chow) versus Marjoram (2\%) and Fennel (1\%) versus Dill (1.2\%). Within each pair, trained odors were balanced across animals within groups.

\section{Training}

Subjects were allowed to habituate to the testing room for $10 \mathrm{~min}$. Subsequently, a demonstrator animal that had just eaten ground chow laced with an odorant (e.g., Clove) was introduced into the subject's cage. Demonstrator animals were used only if they had eaten at least $1 \mathrm{~g}$ of odorant-laced chow within the last $30 \mathrm{~min}$. Subjects were allowed to interact with the demonstrator for 20 min, after which the demonstrator was removed. This procedure was repeated twice more at $1-\mathrm{h}$ intervals by using different demonstrators and the same odorant each time.

\section{Testing: 15-Min Delay}

Subjects remained in the testing room, and were presented with two cups containing ground rat chow 10-15 min after the last demonstrator had been removed. The chow in one cup was laced with the same odorant that the three demonstrators had eaten (e.g., Clove), whereas the chow in the second cup was laced with a different odorant (e.g., Marjoram). The subject was allowed to eat for $45 \mathrm{~min}$, after which cups were weighed to determine how much the rat had eaten from each cup. A preference score for the trained odor (e.g., Clove) was calculated as follows: (weight of food laced with Clove eaten/weight of all food eaten $) \times 100$.

\section{Testing: 1-Wk Delay}

One week after training and 15-min testing, animals were again brought to the testing room, and allowed to habituate for $10 \mathrm{~min}$. They were then presented with two cups as described earlier. The procedure was repeated the following day, and the mean preference score for the $2 \mathrm{~d}$ was calculated. The location of the trained odor (left or right) was balanced across animals and across testing episodes.

\section{Spatial Delayed Alternation}

Rats were trained in a T-maze placed on a pedestal $1.1 \mathrm{~m}$ high. Each arm was $70-\mathrm{cm}$ long and $12-\mathrm{cm}$ across. The transparent Plexiglas maze walls were $16.5-\mathrm{cm}$ high. Animals were pretrained by exposure to the maze with small pieces of Froot Loops (each 1/3 to 1/4 of a Froot Loop) scattered on the start arm and both choice arms. Once they retrieved and ate Froot Loops consistently, the Froot Loops were restricted to the choice arms, then to the end of the choice arms, and eventually to small cups at the ends of the choice arms. This shaping period lasted from 2-4 d. On the last day of pretraining, a transparent plexiglas door was used to block the entrance to either the left or right choice arm (alternating between trials).

Each training trial consisted of a sample phase and a choice phase. In the sample phase, one choice arm was blocked, a Froot Loop was placed in a cup at the end of the open arm, and the animal was placed in the start arm. Thus the animal was forced to traverse the maze in one direction to receive a food reward. The block was then removed and the animal was returned to the start arm. In the choice phase, a Froot Loop was placed in a cup at the end of the previously blocked arm, and the animal could receive another reward by selecting that arm. Six trials per day were conducted. On days 1-3, animals were moved directly from the end of the choice phase to the start arm, so that the delay between retrieving and eating the sample Froot Loop and coming to the choice point was approximately 5-8 sec. On days 4-6, a 5-min delay intervened between the sample and choice trials, during which the

Table 2. Extent of Damage in the Three Lesion Groups

\begin{tabular}{lcccc}
\hline & Hippocampus & Subiculum & Entorhinal & $\begin{array}{r}\text { Perirhinal/ } \\
\text { postrhinal }\end{array}$ \\
\hline H $(n=8)$ & $97 \%-0.7 \%$ & $53 \%-6.5 \%$ & $4 \%-3.2 \%$ & $0 \%$ \\
PS $(n=7)$ & $95 \%-1.4 \%$ & $89 \%-3.1 \%$ & $18 \%-5.2 \%$ & $0 \%$ \\
PHR $(n=16)$ & $1.4 \%-1.3 \%$ & $18 \%-5.7 \%$ & $84 \%-3.3 \%$ & $72 \%-3.5 \%$ \\
\hline
\end{tabular}

Mean-s.e.m.

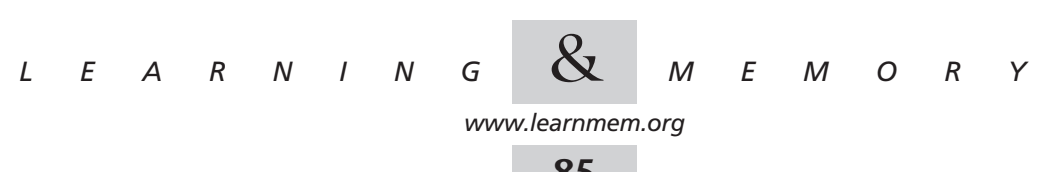


animal was returned to his home cage. The number of errors (selecting the sample arm during the choice phase) was recorded each day.

\section{Histology}

Animals were deeply anesthetized with an overdose $(100 \mathrm{mg} / \mathrm{kg})$ of sodium pentobarbital and perfused transcardially with $0.9 \%$ saline followed by $10 \%$ buffered formalin. Brains were removed and postfixed in formalin for at least $24 \mathrm{~h}$, then submerged in a $20 \%$ glycerol solution $24 \mathrm{~h}$ before sectioning. Coronal $50-\mu \mathrm{m}$ slices were cut on a freezing, sliding microtome, mounted, and stained with thionin. For each animal, the lesions were traced on plates from a rat brain stereotaxic atlas (Paxinos and Watson 1998) spaced 1-mm apart from bregma -1.3 to bregma -8.3 . The total areas of $\mathrm{H}, \mathrm{S}$, entorhinal, and perirhinal/postrhinal cortex (defined here as areas 35 and 36 together) were measured on the tracings, and for each animal the extent of sparing of each of these areas was calculated by dividing the remaining area by the total area in the original plates representing a normal brain.

\section{Data Analysis}

Unpaired $t$-tests were used to compare the extent of the damage between the $\mathrm{H}$ and HS groups. Two-way ANOVAs (delay $\times$ lesion group) were used to compare performance on behavioral measures. Where appropriate, post-hoc Newman/Keuls tests were performed. Significance levels were set at 0.05 .

\section{ACKNOWLEDGMENTS}

We thank Anna A. Allen for assistance with behavioral testing and histological analyses. This work was supported by NRSA grant F32 MH11339 to P.A. and NIMH grant MH 52090 to H.E.

The publication costs of this article were defrayed in part by payment of page charges. This article must therefore be hereby marked "advertisement" in accordance with 18 USC section 1734 solely to indicate this fact.

\section{REFERENCES}

Alvarez, P., Zola-Morgan, S., and Squire, L.R. 1995. Damage limited to the hippocampal region produces long-lasting memory impairment in monkeys. J. Neurosci. 15: 3796-3807.

Beck, M. and Galef, B.G. 1989. Social influences on the selection of a protein-sufficient diet by Norway rats (Rattus norvegicus). J. Comp. Psychol. 103: 132-139.

Bunsey, M. and Eichenbaum, H. 1995. Selective damage to the hippocampal region blocks long-term retention of a natural and nonspatial stimulus-stimulus association. Hippocampus 5: 546-556. . 1996. Conservation of hippocampal memory function in rats and humans. Nature 379: 255-257.

Burton, S., Murphy, D., Qureshi, U., Sutton, P., and O'Keefe, J. 2000. Combined lesions of hippocampus and subiculum do not produce deficits in a nonspatial social olfactory memory task. J. Neurosci. 20: 5468-5475.

Dusek, J.A. and Eichenbaum, H. 1997. The hippocampus and memory for orderly stimulus relations. Proc. Natl. Acad. Sci. 94: 7109-7114.

- 1998. The hippocampus and transverse patterning guided by olfactory cues. Behav. Neurosci. 112: 762-771.

Eichenbaum, H., Stewart, C., and Morris, R.G. 1990. Hippocampal representation in place learning. J. Neurosci. 10: 3531-3542.

Eichenbaum, H., Otto, T., and Cohen, N.J. 1992. The hippocampus-What does it do? Behav. Neural. Biol. 57: 2-36.
- 1994. Two functional components of the hippocampal memory system. Behavioral and Brain Sciences 17: 449-518.

Galef, B.G. and Stein, M. 1985. Demonstrator influences on observer diet preference: Analyses of critical social interactions and olfactory signals. Anim. Learn. Behav. 13: 31-38.

Galef, B.G. and Wigmore, S.R. 1983. Transfer of information concerning distant foods: A laboratory investigation of the "information-centre" hypothesis. Ann. Behav. 31: 748-758.

Galef Jr., B.G., Mason, J.R., Preti, G., and Bean, N.J. 1988. Carbon disulfide: A semiochemical mediating socially-induced diet choice in rats. Physiol. Behav. 42: 119-124.

Kogan, J.H., Frankland, P.W., Blendy, J.A., Coblentz, J., Marowitz, Z., Schutz, G., and Silva, A.J. 1997. Spaced training induces normal long-term memory in CREB mutant mice. Curr. Biol. 7: 1-11.

Mayeux-Portas, V., File, S.E., Stewart, C.L., and Morris, R.J. 2000. Mice lacking the cell adhesion molecule Thy- 1 fail to use socially transmitted cues to direct their choice of food. Curr. Biol. 10: 68-75.

Moser, M.B., Moser, E.I., Forrest, E., Andersen, P., and Morris, R.G. 1995. Spatial learning with a minislab in the dorsal hippocampus. Proc. Natl. Acad. Sci. 92: 9697-9701.

Mumby, D.G. and Pinel, J.P. 1994. Rhinal cortex lesions and object recognition in rats. Behav. Neurosci. 108: 11-18.

Nadel, L. 1991. The hippocampus and space revisited. Hippocampus 1: 221-229.

O'Keefe, J. and Nadel, L. 1978. The hippocampus as a cognitive map. Oxford University Press, New York.

Paxinos, G. and Watson, C. 1998. The rat brain in stereotaxic coordinates, 4th ed. Academic Press, San Diego, CA.

Rampon, C., Jiang, C.H., Dong, H., Tang, Y.P., Lockhart, D.J., Schultz, P.G., Tsien, J.Z., and Hu, Y. 2000. Effects of environmental enrichment on gene expression in the brain. Proc. Natl. Acad. Sci. 97: $12880-12884$.

Schacter, D.L. and Tulving, E. 1994. What are the memory systems of 1994? In Memory systems 1994 (eds. D.L. Schacter and E. Tulving) pp. 1-38. MIT Press, Cambridge, MA.

Squire, L.R. 1992. Memory and the hippocampus: A synthesis from findings with rats, monkeys, and humans. Psychol. Rev. 99: 195-231.

Squire, L.R., Zola-Morgan, S., and Alvarez, P. 1994. Functional distinctions within the medial temporal lobe memory system: What is the evidence? Behav. Brain Sci. 17: 495-496.

Strupp, B.J. and Levitsky, D.A. 1984. Social transmission of food preferences in adult hooded rats (Rattus norvegicus). J. Comp. Psychol. 98: 257-266.

Sutherland, R.J. and Rudy, J.W. 1989. Configural association theory: The role of the hippocampal formation in learning, memory, and amnesia. Psychobiology 17: 129-144.

Whishaw, I.Q. and Jarrard, L.E. 1996. Evidence for extrahippocampal involvement in place learning and hippocampal involvement in path integration. Hippocampus 6: 513-524.

Whishaw, I.Q. and Tomie, J.A. 1997. Perseveration on place reversals in spatial swimming pool tasks: Further evidence for place learning in hippocampal rats. Hippocampus 7: 361-370.

Winocur, G. 1990. Anterograde and retrograde amnesia in rats with dorsal hippocampal or dorsomedial thalamic lesions. Behav. Brain Res. 38: $145-154$.

Winocur, W., McDonald, R.M., and Moscovitch, M. 2001. Anterograde and retrograde amnesia in rats with large hippocampal lesions. Hippocampus 11: 18-27.

Zola-Morgan, S., Squire, L.R., and Ramus, S.J. 1994. Severity of memory impairment in monkeys as a function of locus and extent of damage within the medial temporal lobe memory system. Hippocampus 4: 483-495.

Received December 8, 2000; accepted in revised form February 2, 2001

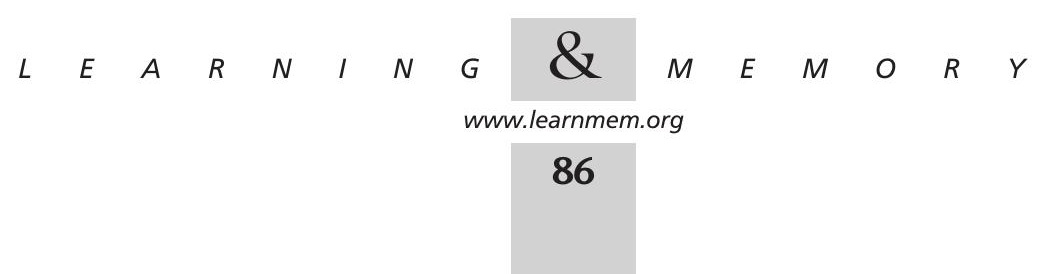




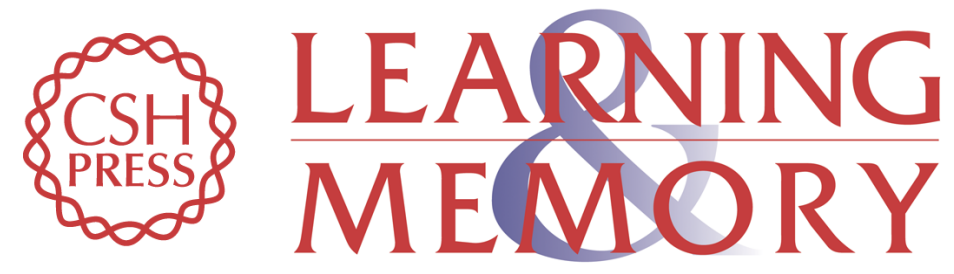

\section{Differential Effects of Damage within the Hippocampal Region on Memory for a Natural, Nonspatial Odor-Odor Association}

Pablo Alvarez, Paul A. Lipton, Rebecca Melrose, et al.

Learn. Mem. 2001, 8:

Access the most recent version at doi:10.1101//m.38201

References This article cites 26 articles, 6 of which can be accessed free at: http://learnmem.cshlp.org/content/8/2/79.full.html\#ref-list-1

License

Email Alerting Receive free email alerts when new articles cite this article - sign up in the box at the Service top right corner of the article or click here. 